sativum L.) / S. Zheng, B. Henken, A. Krens, C. Kik // In Vitro CellDev Biol. 39, 2003. P.288-292.

21. Luciani G. 2006. Effects of explants andgrowth regulators in garlic callus formation and plant regeneration/G. Luciani, A. Mary, C. Pellegrini, N. Curvetto // Plant CellTissue Organ Cult. 87, 2006. - P.139-143.

22. Xu Z. Effect of plant growth regulators,temperature and sucrose on shoot proliferation from the stem disc of Chinesejiaotou (Allium chinense) and in vitro bulblet formation $/ \mathrm{Z}$. Xu, Y. Yeong-Cheol, C. Kim // Acta Physiol. Plant. 30, 2008. - P.521-528.

23. Hailekidan B. In vitro plantlet regeneration fromthe bulbs of shallot (Allium Cepa Var. Group Aggregatum) / B. Hailekidan, M. Andargie, K. Assefa // Res. Plant Sci., 2013. $-1(2) .-$ P.45-52.

DOI 10.18699/GPB2020-124

\title{
Изучение длины вегетационного периода у линий различного генетического происхождения в условиях Ташкентской, Ферганской и Кашкадарьинской областей
}

Эгамбердиева С.А., д.с.-х.н., с.н.с.; Жураев С.Т., к.с.-х.н., с.н.с.

Научно-исследовательский институт селекции, семеноводства и агротехнологии выращивания хлопка, Ташкентская область, Узбекистан.

*e-mail: saida-68@mail.ru

Проведен сравнительный анализ длины вегетационного периода у 10 линий хлопчатника, с обогащенной генетической основой в трех областях Узбекистана. Среди них выделень линии, стабильно проявившие скороспелость по регионам.

Ключевые слова: хлопчатник, скороспелость, адаптивность, интрогрессивные формы, сортоиспьтание.

\section{Study of the length of the growing season in lines of various genetic origin in the conditions of Tashkent, Ferganaand Kashkadarya regions}

Egamberdieva Saida Abdisamatovna, Zhuraev Sirojiddin Turdikulovich Cotton breeding, seed production and agricultural technologies research institute, Tashkent Region, Uzbekistan.

A comparative analysis of the length of the growing season in 10 lines of cotton, with an enriched genetic base in three regions of Uzbekistan, was carried out. Among them, lines were identified that stably showed early maturity in the regions.

Key words: cotton, maturity, adaptability, introgressive forms, variety testing. 
При создании новых сортов сельскохозяйственных культур одним из приемов выявления форм с широкими приспособительными способностями является одновременная оценка генотипов в ряде географических пунктов [2].

Известно, что сорта с обогащенной генетической основой, выведенные благодаря привлечению в селекционный процесс большого числа ценных исходных форм, в том числе из мировой коллекции хлопчатника (ген. ресурсы), включая дикие и полудикие виды и разновидности хлопчатника, обладают лучшей адаптивной способностью к почвенно-климатическим условиям [1].

Используя линии хлопчатника вида G. hirsutum L., полученные на основе интрогрессивных форм с высокими параметрами качества, выхода волокна и урожайности непосредственно в регионах возделывания, нами предполагалось создание сортов, адаптированных к местным почвенно-климатическим условиям, превышающих показатели районированных сортов.

Для проведения исследований были отобраны наиболее продуктивные индивидуальные отборы 10 линий различного генетического происхождения. Каждый индивидуальный отбор был разделен на три части и их семена были высеяны в трех разных экологических зонах - Ташкентской, Ферганской и Кашкадарьинской областях республики.

Ташкентская область имеет три различных климатических условия, но преобладают Csa согласно классификации климата Кеппен-Гейгера. Температура здесь в среднем за год $14,6{ }^{\circ} \mathrm{C}$ и 429 мм - среднегодовая норма осадков. В Куве (Ферганская область) превалирует климат степей. В течение всего года осадков мало. Этот климат считается BSk по классификации климата Кеппен-Гейгера. Среднегодовая температура $14,1^{\circ} \mathrm{C}$. Выпадает около 220 мм осадков в год. Кашкадарьинская область имеет два различных климатических условия, но преобладают BSk. Классификация климата Касби по Кеппен-Гейгеру составляет BSk. Средняя температура воздуха $15,7^{\circ} \mathrm{C}$. В год выпадает около 212 мм осадков [3].

Опыты закладывались рендомизированно, в четырех повторностях. Скороспелость у линий и стандартных сортов изучалась нами по установлению даты созревания коробочек у $50 \%$ растений.

Линия Л-595 во всех трех регионах оказалась самой позднеспелой. Длина вегетационного периода достигала у нее от 120,0 дней в Кашкадарьинском регионе до 139,3 в Ташкентском и 141,3 дня в Ферганском регионах (табл. 1). Наиболее скороспелой в Ташкентском регионе оказалась линия Л481 - 50 \% раскрытия коробочек приходилось на 122 день, в Ферганской области - линия Л-765 созревала за 117,8 дня. В Кашкадарьинской области короткая длина вегетационного периода была отмечена у линий Л-655 и Л-765 и равнялась 101,0 и 101,5 дня соответственно. Таким образом, линия Л-765 явилась наиболее скороспелой по сравнению с изученными линиями, и это свойство она проявила во всех регионах. 
Таблица 1 - Длина вегетационного периода у линий хлопчатника (2019 г.)

\begin{tabular}{|c|c|c|c|c|c|c|}
\hline Регион & № Линии & $\mathrm{n}$ & $\tilde{x}$ (дни) & $\mathrm{S}$ & $\mathrm{S}^{2}$ & V\% \\
\hline \multirow{12}{*}{$\begin{array}{l}\text { Ташкент } \\
\text { (Салар) }\end{array}$} & 481 & 59 & 122,3 & 6,26 & 39,13 & 5,12 \\
\hline & 595 & 55 & 139,3 & 6,14 & 37,65 & 4,41 \\
\hline & 655 & 54 & 122,5 & 5,28 & 27,92 & 4,31 \\
\hline & 681 & 59 & 129,8 & 5,03 & 25,30 & 3,88 \\
\hline & 705 & 65 & 125,0 & 5,39 & 29,04 & 4,31 \\
\hline & 752 & 63 & 132,0 & 5,45 & 29,71 & 4,13 \\
\hline & 765 & 62 & 124,0 & 5,96 & 35,53 & 4,81 \\
\hline & 782 & 49 & 133,3 & 5,50 & 30,27 & 4,13 \\
\hline & 956 & 59 & 137,3 & 6,71 & 45,07 & 4,89 \\
\hline & 998 & 63 & 125,3 & 2,06 & 4,25 & 1,65 \\
\hline & St. Наманган 77 & 60 & 125,4 & 3,34 & 11,15 & 2,66 \\
\hline & St. C-6524 & 54 & 124,2 & 3,85 & 14,82 & 3,10 \\
\hline \multirow{12}{*}{$\begin{array}{c}\text { Фергана } \\
\text { (Кува) }\end{array}$} & 481 & 54 & 119,8 & 8,43 & 71,02 & 7,04 \\
\hline & 595 & 51 & 141,3 & 8,44 & 71,17 & 5,97 \\
\hline & 655 & 32 & 119,3 & 7,38 & 54,52 & 6,19 \\
\hline & 681 & 57 & 132,3 & 7,26 & 52,66 & 5,49 \\
\hline & 705 & 61 & 121,5 & 7,52 & 56,61 & 6,19 \\
\hline & 752 & 58 & 132,8 & 7,75 & 60,03 & 5,84 \\
\hline & 765 & 53 & 117,8 & 8,33 & 69,40 & 7,07 \\
\hline & 782 & 61 & 132,8 & 7,10 & 50,45 & 5,35 \\
\hline & 956 & 59 & 137,0 & 8,63 & 74,50 & 6,30 \\
\hline & 998 & 44 & 121,5 & 1,00 & 1,00 & 0,82 \\
\hline & St. Наманган 77 & 54 & 118,4 & 2,25 & 10,56 & 1,90 \\
\hline & St. C-6524 & 54 & 120,0 & 3,47 & 19,98 & 2,89 \\
\hline \multirow{12}{*}{$\begin{array}{c}\text { Кашкадарья } \\
\text { (Касби) }\end{array}$} & 481 & 51 & 103,0 & 7,41 & 54,85 & 7,19 \\
\hline & 595 & 53 & 120,0 & 7,40 & 54,74 & 6,17 \\
\hline & 655 & 55 & 101,0 & 6,83 & 46,67 & 6,76 \\
\hline & 681 & 53 & 113,5 & 6,54 & 42,81 & 5,76 \\
\hline & 705 & 57 & 106,0 & 6,87 & 47,19 & 6,48 \\
\hline & 752 & 56 & 113,5 & 7,34 & 53,89 & 6,47 \\
\hline & 765 & 52 & 101,5 & 7,90 & 62,38 & 7,78 \\
\hline & 782 & 56 & 114,0 & 7,52 & 56,61 & 6,60 \\
\hline & 956 & 45 & 118,5 & 8,80 & 77,43 & 7,43 \\
\hline & 998 & 64 & 102,5 & 1,00 & 1,00 & 0,98 \\
\hline & St. Наманган 77 & 44 & 112,5 & 1,14 & 1,56 & 1,00 \\
\hline & St. C-6524 & 56 & 113,8 & 1,38 & 2,16 & 2,00 \\
\hline
\end{tabular}

Это свидетельствует о высокой генетической детерминированности 
признака у данной линии. Линия Л-481 также проявила стабильную скороспелость по регионам.

В результате двухфакторного дисперсионного анализа с повторениями выявлены существенные различия между изученными линиями по длине вегетационного периода. Наибольшее влияние на признак оказал фактор среды 60 \% (табл. 2). Доля влияния генотипа равнялась в наших опытах $36 \%$. Влияние взаимодействия генотип-среда на показатели признака несущественно - $1 \%$. Доля неучтенных факторов также оказалась малосущественной $-3 \%$.

Таблица 2 - Двухфакторный дисперсионный анализ длины вегетационного периода у линий хлопчатника

\begin{tabular}{|c|c|c|c|c|c|c|}
\hline $\begin{array}{c}\text { Источник } \\
\text { вариации }\end{array}$ & $S S$ & $d f$ & $M S$ & $F$ & Р-Значение & $\begin{array}{c}\text { F критиче- } \\
\text { ское }\end{array}$ \\
\hline Выборка & 5738.742 & 9 & 637.638 & 110.4135 & $1.08 \mathrm{E}-44$ & 1.985595 \\
\hline Столбцы & 9632.217 & 2 & 4816.108 & 833.9582 & $8.24 \mathrm{E}-59$ & 3.097698 \\
\hline Взаимодействие & 176.2833 & 18 & 9.793519 & 1.695847 & 0.054512 & 1.719592 \\
\hline Внутри & 519.75 & 90 & 5.775 & & & \\
\hline Итого & 16066.99 & 119 & & & & \\
\hline
\end{tabular}

Известно, что длина вегетационного периода колеблется в зависимости от погодных и климатических факторов. В наших опытах длина вегетационного периода испытываемых линий в Ташкентской области в среднем равнялась 129 дням, в Ферганской области - 127,5 дня и в Кашкадарьинской области растения созревали за 109,4 дня, что соответствует климатическим условиям регионов.

В результате испытаний выделены линии Л-765, Л-481 и Л-655 оказавшиеся наиболее скороспелыми по сравнению с другими изученными линиями и стандартными сортами во всех трех регионах.

\section{Список литературы}

1. Иксанов М.И., Алиходжаева С.С., Амантурдиев А. О высоком качестве волокна сортов хлопчатника узбекской селекции // М.И. Иксанов, С.С. Алиходжаева, А.Амантурдиев. Сельское хозяйство Узбекистана. AGRO ILM. № 2. 2014. С. 5-6.

2. Кильчевский А.В., Хотылева Л.В. Экологическая селекция растений / А.В.Кильчевский, Л.В. Хотылева - Минск: Технология, 1997. - 372 с.

3. https://ru.climate-data.org/ 